\title{
PROSES KREATIF TARI BEDAYA PUTRI PAKUNGWATI KERATON KASEPUHAN CIREBON KARYA SULTAN SEPUH XIV PANGERAN RAJA ADIPATI ARIEF NATADININGRAT
}

\author{
Oleh: Dian Rahayu \\ Email: dianrhyu99@gmail.com \\ Pembimbing Tugas Akhir: Dra. Budi Astuti, M.Hum. dan Dra. Sri Hastuti, M.Hum.
}

\begin{abstract}
RINGKASAN
Penelitian ini bertujuan untuk mengetahui dan mengkaji proses kreatif tari bedaya Putri Pakungwati karya Sultan Sepuh XIV Pangeran Raja Adipati Arief Natadiningrat, tarian yang terilhami oleh dokumentasi yang dimiliki oleh Keraton Kasepuhan berupa foto-foto. Teknik pengumpulan data yang digunakan adalah observasi, wawancara, studi pustaka, dan dokumentasi. Observasi dilakukan untuk mengamati objek secara langsung yang diteliti saat melakukan penelitian, wawancara dilakukan melalui proses tanya jawab secara lisan, bertatap muka dengan narasumber yang diperlukan, studi pustaka berupa sumber tertulis yang diperoleh dari beberapa buku yang sesuai dengan permasalahan untuk membantu penulisan dan kerangka berpikir.

Hasil penelitian menunjukan bahwa, dalam karya tari Bedaya Putri Pakungwati, menghadirkan nafas-nafas baru untuk tari yang ada di Cirebon khususnya tari bedaya. Secara keseluruhan ada banyak unsur kreatif yang tertuang dalam karya tari Bedaya Putri Pakungwati. Terlihat dari konsep rancangan ide garapan, materi gerak tari yang berasal dari pengembangan gerak gaya Cirebonan, iringan tari yang terinspirasi dari iringan yang ada di Keraton Kasepuhan, kostum yang mengambil konsep islami hingga properti yang disajikan.
\end{abstract}

Kata Kunci: Proses Kreatif, Sultan Sepuh XIV Pangeran Raja Adipati Arief Natadiningrat, Bedaya Putri Pakungwati

\section{ABSTRACT}

This research have purpose to find and analize the process of Putri Putri Pakungwati Bedaya Dance by Sultan Sepuh XIV Pangeran Raja Adipati Arief Natadiningrat, dance that inspired by photo documentation that owned by Keraton Kasepuhan. Using data collecting technique like observation, interview, literature, review, documentation. Observation for observasing object directly when doing research. Interiew for having process question and answer orally, face to face with interviewees needed, literature review like written sources that taken from few books that suitable with problem to help writing and design thinking.

The result of research shows that ini Putri Pakungwati Bedaya Dance gives new knowledge for dance in Cirebon, there are many creative element in Putri Pakungwati Bedaya Dance. Seen from the idea of arable design concept, dance mves material from Cirebon style moves development, music for dance that inspired from music in Keraton Kasepuhan, and costume andproperty using Islamic concept.

Keywords: Creative Process, Sultan Sepuh XIV Pangeran Raja Adipati Arief Natadiningrat, Putri Pakungwati Bedaya. 
I.

Cirebon berasal dari kata caruban, lalu berubah menjadi carbon atau cerbon, dan akhirnya menjadi Cirebon. Caruban berari campuran, karena tempat ini dihuni oleh berbagai bangsa, agama, bahasa dan tulisan yang berbeda-beda sesuai dengan bawaannya masing-masing (Lalan Ramlan, 2008: 21-22). Adapun Cirebon secara kiratabasa terdiri dari dua suku kata, yaitu „, $c i^{\text {ee }}$ dalam bahasa Sunda yang berarti air (cai; ci), dan kata ,rebon yaitu sejenis udang kecil yang biasa dipakai sebagai bahan dalam pembuatan terasi (Lalan Ramlan, 2008: 22). Pengertian secara harafiah arti Cirebon adalah air rebon (udang kecil). Makanya mengandung pengertian Cirebon sebagai kota udang. Kota Cirebon memang terkenal sebagai kota penghasil terasi dan hasil laut.

Cirebon memang berbeda dengan Sunda maupun Jawa. Meskipun kedua kebudayaan besar itu banyak mempengaruhi tumbuh dan berkembangnya Cirebon (M. Noer, 2009:2). Cirebon memiliki beberapa keraton yaitu Keraton Kasepuhan, Keraton Kanoman, Keraton Kacirebonan dan Keprabonan. Dalam lingkungan Keraton Cirebon ada keturunan Raja yang menjabat sebagai Sultan Cirebon. Salah satu keraton tertua di Cirebon adalah Keraton Kasepuhan, Kasepuhan artinya tempat sepuh atau tertua. Sampai sekarang Sultan Kasepuhan bergelar Sultan Sepuh. Keraton Kasepuhan memiliki kesenian diantaranya kesenian Tayub, Sintren, Topeng Cirebon, Ronggeng Pesisir dan tari bedaya. Pada saat ini yang sedang berkembang adalah Bedaya Putri Pakungwati.

Tari Bedaya Putri Pakungwati diciptakan pada tahun 2010 oleh Sultan Sepuh XIV Pangeran Raja Adipati Arief Natadiningrat. Sultan memerintahkan kepada pengajar SMK Pakungwati yaitu Bapak Inu dan Ibu Rohaeni untuk membuat tari Bedaya Putri Pakungwati. Tari Bedaya Putri Pakungwati diciptakan untuk kepentingan Festival Keraton se-Indonesia di Palembang yang diselenggarakan pada tahun 2010.
Setelah itu, bedaya Putri Pakungwati juga dipentaskan untuk persembahan saat acaraacara tradisi di Keraton Kasepuhan, seperti penyambutan tamu saat mengunjungi Keraton. Tujuan Sultan Sepuh XIV menciptakan bedaya Putri Pakungwati sebagai upaya agar Keraton Kasepuhan mempunyai identitas serta juga sebagai bukti karya masa kekuasaan Sultan Sepuh XIV.

Bedaya Putri Pakungwati menceritakan sosok salah satu istri dari Syekh Syarif Hidayatullah yang bergelar Sunan Gunung Jati yaitu Nyi Mas Ratu Pakungwati dan simbol dari sejarah Keraton pertama kali yaitu Keraton Pakungwati. Nyi Mas Ratu Pakungwati disimbolkan sebagai sosok perempuan yang cantik dan elok budi dengan mempunyai karakter yang heroik, berani, tegas. Karakter yang dimiliki oleh Nyi Mas Ratu Pakungwati terlihat saat kemelut besar masjid Agung Sang Cipta Rasa terbakar, beliau ikut serta memadamkan api dan meninggal di dalam masjid tersebut. Sehingga, sampai saat ini salah satu istri Sunan Gunung Jati menjadi salah satu tokoh pahlawan Islam di Cirebon.

Bedaya Putri Pakungwati mempunyai durasi 10 menit. Secara struktural bentuk Bedaya Putri Pakungwati pementasannya terbagi menjadi tiga bagian yaitu dodoan, tengahan dan geder/kering. Bagian dodoan yaitu awalan/pembukaan dengan jalan perlahan/mlaku soder menuju area menari lalu duduk sembah, menggambarkan pengawalan yang serba pelan dan hati-hati. Bagian tengahan menggambarkan ditengah-tengah perjalanan hidup, perjalanan spiritual seorang putri banyak tindakan yang harus dikerjakan dengan cekatan dan energik. Sehingga, bagian tengahan penghantar inti cerita dari bedaya Putri Pakungwati dengan gerak yang lebih dinamis dan tempo yang semakin cepat. Bagian geder/kering merupakan inti cerita dari tarian, bagian ini menggambarkan berlatih kanuragan penari tokoh Nyi Mas Ratu Pakungwati dan dayang - dayangnya, menyimbolkan perang tanpa ada kalah dan menang dengan keris atau sampur. 
Bedaya Putri Pakungwati adalah komposisi tari putri berjumlah sembilan, namun pada pementasan pada berbagai acara banyak ditemukan formasi penari dengan jumlah tiga, lima dan tujuh. Makna jumlah sembilan diambil dari kaitannya dengan jumlah Wali Sanga tokoh-tokoh penyebar agama Islam di Jawa khususnya di Cirebon (Sunan Gresik, Sunan Ampel, Sunan Bonang, Sunan Drajat, Sunan Giri, Sunan Muria, Sunan Kudus, Sunan Kalijaga, dan Sunan Gunung Jati) dan sembilan lubang kehidupan yang terdapat pada tubuh manusia yaitu dua lubang mata, dua lubang telinga, dua lubang hidung, dua lubang pelepasan (depan dan belakang), dan satu lubang mulut (Sultan Sepuh XIV, wawancara 20 Maret 2016, diijinkan dikutip). Jumlah tiga mempunyai makna Insan Kamil yaitu Iman, Islam, Ihsan (Sultan Sepuh XIV, wawancara 20 Maret 2016, diijinkan dikutip). Iman adalah keyakinan dalam hati untuk diucapkan oleh lisan dan diwujudkan dalam amal perbuatan meliputi enam rukun Iman yaitu iman kepada Allah, Malaikat, Kitab, Nabi \& Rasul, hari akhir/Kiamat, dan Qada \& Qadar. Islam dijelaskan dengan penjabaran lima rukun Islam Syahadat, Solat, Puasa, Zakat, dan menunaikan Haji. Ihsan merupakan pengaplikasian dari Iman dan Islam. Jumlah lima mempunyai makna Rukun Islam yaitu Syahadat, Sholat, Puasa, Zakat dan menunaikan Haji. Rukun Islam dijelaskan pada Hadist diriwayatkan Ibnu Umar r.a, dari Nabi SAW. Beliau bersabda: "Islam didirikan atas lima rukun: (1) Mengesakan Allah, (2) Mendirikan Shlat, (3) Membayar Zakat, (4) Puasa Ramadhan, (5) Haji. Para Sahabat bertanya, "Apakah urutannya haji dulu lalu puasa Ramadhan?" Rasulullah menjawab: "Tidak, puasa Ramadhan kemudian Haji. (Imam Al-Mundziri, 2003:36). Formasi penari berjumlah tujuh mempunyai makna tujuh lapis langit ciptaan Allah (Sultan Sepuh XIV, wawancara 20 Maret 2016, diijinkan dikutip). Terdapat pada ayat yang artinya sebagai berikut: "Dialah (Allah) yang menciptakan segala apa yang ada di bumi untuk mu kemudian Dia menuju ke langit, lalu Dia menyempurnakannya menjadi tujuh langit. Dan Dia Maha Mengetahui segala sesuatu." (Q.S. Al-Baqarah 2:29), dalam ayat tersebut Allah menyebut adanya tujuh langit ciptaan Allah SWT.

Jumlah penari bedaya Putri Pakungwati diharuskan dengan jumlah ganjil. Menurut Sultan Sepuh XIV, makna ganjil mengambil dari filosofi yaitu bahwa Tuhan ganjil dan Tuhan mencintai angka ganjil (Sultan Sepuh XIV, wawancara 20 Maret 2016, diijinkan dikutip). Dalam sebuah hadist Rasullullah SAW yang artinya "Sesungguhnya Allah SWT itu witir dan Dia mencintai yang witir (ganjil)" (HR Bukhari dan Muslim). Dalam hadist tersebut dijelaskan bahwa Allah itu witir, artinya Allah itu Esa tidak ada sekutu yang serupa bagi-Nya. Sedangkan makna Allah mencintai witir adalah bahwa Allah mengutamakan bilangan ganjil dalam beberapa amalan dan ketaatan. Untuk pementasan jumlah penari sembilan, tujuh, lima dan tiga dalam aspek gerak maupun iringan tidak ada yang berubah hanya saja pola lantai yang berubah. Tari bedaya Putri Pakungwati dalam bentuk penyajiannya terdapat satu penari sebagai tokoh dan sisa penari lainnya sebagai penari dayang.

Tempat pementasan tari Bedaya Putri Pakungwati dilaksanakan di Bangsal Prabayaksa untuk menyambut tamu-tamu penting Sultan Sepuh XIV dan Bangsal Pagelaran, dipentaskan untuk acara-acara pagelaran yang diadakan Keraton Kasepuhan Cirebon. Untuk latihan tarian tersebut dilaksanakan di Bangsal yang berada di Gua Sunyaragi. Tempat pementasan tari bedaya Putri Pakungwati akan dipentaskan sesuai acara yang diselenggarakan seperti panggung terbuka, namun telah seijin Sultan Sepuh XIV, sehingga bersifat kondisional.

Semenjak keberadaannya, tari Bedaya Putri Pakungwati mengalami suatu proses kreatif agar dapat menghasilkan suatu bedaya yang berbeda dengan yang ada, seperti bedaya yang saat ini masih bertahan di Keraton Kanoman. Proses kreatif Bedaya Putri Pakungwati terilhami oleh dokumentasi yang 
dimiliki oleh Keraton Kasepuhan berupa fotofoto seperti foto dengan jumlah penari sembilan. Di dalam berkesenian, proses kreativitas seorang seniman khususnya seorang pencipta sangatlah bernilai untuk menunjukan kualitas dari karya yang dibuat. Dapat diartikan, suatu proses kreatif merupakan tahapan yang dilalui dalam mencipta sebuah karya untuk menghasilkan suatu karya baru.

Proses kreatif penciptaan maupun pengembangan gerak-gerak bedaya Putri Pakungwati berpijak pada tari tradisi yang sangat lekat dengan gaya Cirebonan. Sultan Sepuh XIV dalam proses kreatif tari bedaya Putri Pakungwati memiliki peran sebagai pencipta tari. Pencipta tari yang memerintahkan untuk membuat sebuah tarian, beliau hanya menentukan pemilihan judul, tema maupun tahap evaluasi-evaluasi. Sedangkan, untuk pembuatan struktur koreografi ditangani oleh penata tari yaitu Ibu Rohaeni dan iringan tari oleh Bapak Inu. Proses kreatif bedaya Putri Pakungwati meliputi aspek-aspek sebagai berikut aspek pemilihan judul, pemilihan gerak, iringan tari, tata rias dan busana, tata panggung, tata cahaya, properti.

Ketertarikan peneliti pada objek ini karena tari bedaya Putri Pakungwati melalui proses kreatif khususnya pada aspek tema dan penuangan gerak yang menggambarkan sosok Nyi Mas Ratu Pakungwati, perempuan yang berani dan heroik dengan peran sertanya memadamkan api saat Masjid Agung Sang Cipta Rasa terbakar. Maka, dapat ditarik rumusan masalah yaitu bagaimana bentuk penyajian tari bedaya Putri Pakungwati dan bagaimana proses kreatif tari bedaya Putri Pakungwati Keraton Kasepuhan Cirebon karya Sultan Sepuh XIV Pangeran Raja Adipati Arief Natadiningrat. Sehingga, penulis menggunakan pendekatan koreografi untuk mengupas tentang permasalahan teks koreografi tari bedaya Putri Pakungwati. Teori Y. Sumandiyo Hadi dalam buku Koreografi: Bentuk-Teknik-Isi digunakan untuk membedah permasalahan koreografi seperti gerak tari, ruang tari, iringan tari, cara penyajian, properti, dan rias busana tari.

II.

Tari Bedaya merupakan sebuah komposisi tari wanita secara kelompok. Tarian ini boleh dikembangkan hanya di dalam lingkungan tembok Keraton. Tari Bedaya yang berkembang di Keraton Cirebon mempunyai nilai religi, karena Cirebon sebagai pusat penyebaran agama Islam oleh Wali Sanga di Jawa Barat. Bedaya Cirebon dapat diartikan bahwa tarian ini mempunyai filosofi yang banyak memuat nuansa Islam dan merupakan hasil budidaya karya manusia yang menciptakannya. Dengan berbagai sumber cerita tariannya diambil dari perjalanan sejarah, peradaban maupun tokoh penting dalam Agama Islam khususnya di Cirebon. Aspek religi yang ada mempengaruhi isi cerita dari tari Bedaya salah satunya yang ada di Keraton Kasepuhan yaitu mengambil tokoh islam Nyi Mas Ratu Pakungwati. Pendapat lain, menurut Inu Kertapati "bedaya berasal dari dua kata yaitu bedar yang berarti memulai dan budaya berarti budaya" (Inu Kertapati, wawancara, 08 Maret 2016, diijinkan dikutip). Tari bedaya merupakan pencarian tarian sebagian harapan memulai bangkitnya budayabudaya Cirebon yang hampir punah khususnya di Keraton Kasepuhan.

Bentuk penyajian merupakan unsur yang penting dalam menyajikan sebuah seni pertunjukan. Pengertian bentuk menurut Lois Ellfeldt dalam bukunya Pedoman Dasar Penata Tari terjemahan Sal Murgiyanto adalah wujud rangkaian gerak atau pengaturan lakulaku (Lois Ellfeldt. 1977:15). Bentuk penyajian bedaya Putri Pakungwati meliputi: gerak, pola lantai, tata rias dan busana, iringan tari, tata panggung, tata cahaya dan properti. Unsur-unsur antara satu dengan yang lain saling terkait, sehingga menjadi satu kesatuan yang terkait dalam suatu pertunjukan.

Secara struktural bedaya Putri Pakungwati terdapat tiga bagian yaitu bagian awal/dodoan, tengahan, deder/kering. Bagian 
awal/dodoan merupakan tahap awal dari pertunjukan tari saat penari memasuki area menari dengan pola irama pelan, motif geraknya yaitu pasang soder, mlaku soder yaitu gerak yang dilakukan penari untuk menuju area menari, ayun pasang soder, mlaku mundur, muter geber soder, adeg-adeg pasang soder, silang buang soder kanan, silang buang soder kiri, muter pasang siji tangan, ukel pasangan, adeg-adeg pasang soder, tumpang tali buang soder, tumpang tali, srisig soder, adeg-adeg pasang soder, buang loro soder, ukel tangan loro, ukel tangan siji, ukel pasangan, buang loro soder, ukel tangan loro, ukel tangan siji, tumpang tali soder, adeg-adeg pasang soder, srisig deruk neba, ayun ukel tangan, pasang siji kiri-kanan, dan ukel pasangan. Bagian tengahan merupakan bagian tengah sebagai penghantar pokok pementasan atau inti cerita yang sudah dilakukan di area menari dengan pola irama sedang. Adapun motif geraknya sebagai berikut: lembeyan, ngola bahu, buang soder, nyawang, ngola bahu, buang soder, dolanan soder, buang soder, ngola bahu, buang soder, tepak bahu tumpang tali, ngola bahu, buang soder, srisig pasang tangan siji. Bagian geder/kering merupakan bagian akhir atau tahap akhir sebagai inti cerita, penyajian terakhir dari seluruh pementasan dengan diakhiri keluarnya penari dari area menari dengan pola irama cepat. Motif pada bagian geder/kering yaitu jukut soder, srisig soder, buang soder 1, srisig soder, muter soder, buang soder 1, srisig soder, dolanan soder, buang soder 1, srisig soder, dolanan soder, buang soder 1, srisig tabe soder, larapan, srisig ngruji, tabe soder, pasangan, lontang kiri-kanan, sembahan, srisig soder menuju keluar area menari.

Tata rias tari bedaya Putri Pakungwati menggunakan corrective make-up dengan goresan alis dan perpaduan warna eyeshadow berwarna hijau yang dicampur dengan biru tua, yang menghasilkan wajah penari terlihat tampak cantik. Hiasan kepala tari bedaya Putri Pakungwati terdiri dari cemoro yang dibentuk menjadi sanggul/gelung, lalu ditutupi dengan rajut melati, bagian bawah sanggul dihiasi gajah muling, kembang goyang dan tusuk konde pada bagian depan sanggul terselipkan mahkota dan aksesoris bros, serta dipadukan dengan ronce mawar bagian kanan dan melati rampe bagian kiri.

Adapun tata busana yang digunakan terdiri dari kebaya berwarna putih tanpa kancing ditutup dengan kemben berwarna hijau, bros dikaitkan sebagai pengganti kancing/hiasan pada kebaya, kain/jarik bermotif megamendung warna hijau dengan dibentuk seperti rok bagian ujung atas kain dilipat dan disatukan di bagian pinggang kanan, lalu diikat menggunakan tali, dan setelah itu ditutupi dengan kemben berwarna hijau. Sabuk yang melilit di pinggang, menggunakan tiga sampur/soder yaitu warna kuning dan hijau yang dimasukkan ke dalam sabuk dengan sisi bagian kiri dan kanan yang simetris. Juntaian sampur bagian belakang dibentuk seperti bunga. Sampur/soder warna merah digunakan di bagian punggung kanan dan dimasukkan dibagian sabuk kiri bagian belakang.

Tarian ini diiringi lagu atau gending pancaniti berlaras pelog yang mempunyai arti panca (lima) dan niti (menata) yang berarti penataan lima unsur dengan anjuran-anjuran berkaitan dengan dakwah Sunan Gunung Jati saat menyebarkan agama Islam yang selalu mengingatkan anjuran-anjuran rukun Islam yaitu syahadat, solat, puasa, zakat dan menunaikan haji. Pola instrumen yang memiliki tiga tahap yaitu pancaniti gamelanan pada bagian awal/ dodoan berirama pelan, barlen bungur bagian tengahan berirama sedang dan sejenis solawatan atau sendal paul (bat-embat) dibagian geder/kering berirama cepat.

Gamelan yang digunakan diberi nama seperangkat gamalen megamendung untuk mengiringi tari bedaya Putri Pakungwati adalah saron, bonang, gong, kendang, kebluk, kenong, demung, suling, rincik/kemnyang, gambang dan kecrek. Musik iringan tari bedaya Putri Pakungwati tidak hanya live saja, 
tetapi bisa menggunakan musik MIDI (Musical Instrument Digital Interface).

III.

Tari bedaya Putri Pakungwati mengalami proses kreatif. Kreativitas dapat diartikan sebagai suatu kemampuan daya cipta yang dimiliki manusia untuk membuat, mengolah, dan mengembangkan sesuatu yang biasa menjadi tidak biasa. Kreativitas juga sering dikaitkan dengan kemampuan seseorang untuk mencari berbagai alternatif baik dalam bentuk pemikiran, pendekatan, masalah ataupun aktifitas. Seolah-olah orang kreatif tidak pernah hilang akal untuk menghasilkan gagasan baru (Suharnan, 2011:1). Kreativitas dapat dipahami sebagai suatu kemampuan untuk mengubah sesuatu yang tidak berarti menjadi sesuatu indah dan bermakna, sesuatu yang biasa menjadi sesuatu yang luar biasa (M. Hawkins, 2003: 3). Bentuk kreativitas yang dihadirkan dalam karya tari bedaya Putri Pakungwati dari sumber cerita sosok Nyi Mas Ratu Pakungwati, dengan gerak yang merupakan pengembangan dari tari dasar putri Cirebonan, dengan memanfaatkan senjata yang digunakan oleh Nyi Mas Ratu Pakungwati yaitu keris dan slendang suwuk, sehingga menghasilkan karya tari yang diinginkan. Proses kreatif bedaya Putri Pakungwati meliputi aspek-aspek sebagai berikut aspek pemilihan judul, pemilihan gerak, iringan tari, tata rias dan busana, tata panggung, tata cahaya, properti.

Penentuan judul sangatlah berpengaruh untuk setiap karya yang telah diciptakan. Sebuah tarian yang telah selesai dan hendak dipertunjukkan dibutuhkan judul atau nama, judul tersebut dibuat ringkas, jelas dan orisinil sehingga secara sekilas dapat ditangkap oleh pengamatnya (Sal Murgiyanto,1983:93). Karya tari Sultan Sepuh XIV diberi judul tari bedaya Putri Pakungwati. Ide yang menjadi fokus Sultan Sepuh XIV untuk memberikan judul bedaya Putri Pakungwati, karena gambaran inti cerita dari tarian tersebut bersumber dari sosok Nyi Mas Ratu
Pakungwati. Gambaran sosok Nyi Mas Ratu Pakungwati dituangkan dengan gerak-gerak seorang putri yang halus dan dinamis. Dengan penyesuaian dari berbagai aspek Sultan Sepuh mendapatkan judul yang cocok dengan konsep ide yang diinginkan yaitu bedaya Putri Pakungwati.

Bedaya Putri Pakungwati melalui tahap proses kreatif yang mengubah motif gerak maupun susunannya. Perubahan motif maupun susunannya diubah sesuai evaluasi dari Sultan Sepuh XIV. Motif-motif yang ada pada struktur awal tampak lebih sederhana, singkat dan banyaknya pengulangan motif. Sehingga, penata tari berinisiatif untuk menghilangkan motif-motif pada struktur awal dan diubah menjadi motif yang baru, tetapi masih ada beberapa motif digunakan namun divariasikan kembali. Struktur sekarang memiliki motifmotif baru yang lebih banyak, pengulangan motif sedikit ditemukan pada hasil struktur sekarang. Perubahan penyusunan motif membuat durasi bedaya Putri Pakungwati lebih lama dibandingkan dengan menggunakan struktur awal hanya 8 menit menjadi 10 menit.

Proses pemilihan iringan bermula terinspirasi dengan iringan yang ada di Keraton Kasepuhan yaitu saat untuk mengiringi Sultan Sepuh saat meninggalkan keraton yaitu Gending Pancaniti. Proses pembuatan iringannya disesuaikan dengan nuansa gending tersebut dan penyesuaian gerak yang telah dibuat oleh penata tari. Berawal dengan ketukan kendhang sebagai patokan tempo setiap geraknya dan diikuti dengan instrumen gamelan lainnya. Gamelan yang digunakan berlaras pelog, pola instrumen yang memiliki tiga tahap yaitu: pancaniti gamelanan untuk mengiringi bagian awal/dodoan dengan irama yang pelan sesuai geraknya, barlen bungur untuk mengiringi bagian tengahan dengan irama sedang, dan sejenis solawatan atau sendal paul (bat-embat) untuk mengiringi bagian geder/kering dengan irama cepat.

Melalui proses kreatif bentuk desain busana bedaya Pakungwati mengalami perubahan sebagai berikut: tahap sebelum 
proses kreatif busana terdiri dari: kebaya berwarna putih dengan lengan batas siku-siku, ampok payet berwarna hijau, kemben berwarna hijau muda dengan motif megamendung, sabuk, keris, tiga soder/sampur warna kuning sebagai aksesoris dibentuk seperti tirai, warna hijau digunakan untuk menari, warna merah sebagai aksesoris, dan celana sontog panjang. Setelah melalui berbagai pertimbangan maka kostum berubah terdiri dari kebaya berlengan panjang berwarna putih, kemben berwarna hijau tua, bros dikaitkan sebagai pengganti kancing/hiasan pada kebaya, kain/jarik bermotif megamendung warna hijau dengan dibentuk seperti rok bagian ujung atas kain dilipat dan disatukan di bagian pinggang kanan, lalu diikat menggunakan tali, kemudian setelah itu ditutupi dengan kemben berwarna hijau tanpa motif, sabuk yang melilit di pinggang, menggunakan tiga sampur/ soder yaitu warna kuning dan hijau dimasukkan kedalam sabuk dengan sisi bagian kiri dan kanan yang simetris. Sampur dikenakan menjuntai dengan bagian belakang dibentuk seperti bunga. Sampur/soder warna merah digunakan di bagian punggung kanan dan dimasukkan di bagian sabuk kiri bagian belakang.

Pertimbangan penata busana mengubah warna hijau muda pada busana yang diinginkan Sultan Sepuh XIV karena tidak sesuai, sehingga menjadi hijau tua untuk kemben tanpa motif dan soder/sampur. Pengurangan penggunaan ampok payet agar bagian atas busana tidak tampak terlalu padat. Perubahan celana sontog menjadi kain yang dibentuk seperti rok, dengan pertimbangan tema tari itu menggambarkan sosok seorang putri walaupun Nyi Mas Ratu Pakungwati berani dan heroik tetapi tetap keanggunan sebagai seorang perempuan tidak hilang. Soder/sampur warna kuning yang berbentuk seperti tirai mengalami perubahan tetap sebagai aksesoris, namun dibentuk menjuntai seperti soder yang digunakan untuk menari.

Sejak proses kreatif konsep tata panggung dan tata cahaya sifatnya kondisional, disesuaikan luasnya panggung untuk pementasan untuk mempermudah penari beradaptasi dengan blocking sesuai situasi dan kondisi tempat pertunjukan. Penggunaan tata cahaya yang berlebihan hanya untuk sekedar penekanan suasana saat malam hari di bagian geder/kering diberi nuansa warna merah sebagai penggambaran keberanian Nyi Mas Ratu Pakungwati.

Selain itu, proses kreatif penata tari atas konsep garapan yang ditentukan melalui proses koreografi yaitu eksplorasi, improvisasi, dan pembentukan. Eksplorasi termasuk berpikir, berimajinasi, merasakan dan merespons (M. Hawkins, 1990:27). Seorang koreografer setelah melakukan tahaptahap sebelumnya yaitu eksplorasi, improvisasi, mulai berusaha "membentuk" atau mentransformasikan bentuk gerak menjadi sebuah tarian atau koreografi (Sumandiyo Hadi, 2012:78). Penata tari mulai menyusun dari motif satu dengan motif yang lain , menetapkan struktur bentuk, dan menjadikannya satu garapan tari. Setelah melalui proses koreografi, dalam pertunjukan tari elemen-elemen pendukung sangat menunjang untuk membantu penata tari dalam proses awal garapan hingga akhir pementasan. Elemen-elemen pendukung tersebut meliputi penari, penata iringan, penata tata rias dan busana, penata panggung dan penata lampu.

Dalam proses koreografi hingga menjadi satu produk pertunjukan tari, keterkaitan atau hubungan penata tari atau koreografer dan penari sangat menentukan keberhasilan suatu pertunjukan (Sumandiyo Hadi, 2012:109). Dalam proses garapan, penata tari (koreografer) dengan memberikan contoh, menata gerak, dan formasi yang pasti. Penentuan formaasi penari, penata dengan pertimbangan postur tubuh agar terlihat seimbang antara penari satu dengan yang lain. Garapan tarian akan berhasil jika melalui tahap general rehearsal untuk penyesuaian penari pada tata panggung maupun formasinya.

Penata tari dengan penata iringan bekerjasama saat proses latihan telah dimulai. Penata tari menyusun motif satu dengan motif yang lain sehingga menjadi satu bagian. 
Setelah membentuk perbagian, penata tari menentukan penempatan bagian-bagian tersebut dan menjadikannya sebuah tarian. Begitu pula dengan penata iringan, membuat beberapa pola iringan dan gambaran tempo iringan tarinya. Pencarian dilakukan secara bersamaan yaitu penata tari membuattarian, dan penata iringan dengan pola iringannya. Penggarapan iringan dilakukan setelah semua struktur koreografi sudah selesai, penata tari memperagakan tari secara bersamaan dengan iringan. Penata tari yang berperan untuk menentukan struktur koreografi yaitu bagian awal, bagian tengah, dan akhir. Penata iringan mengikutinya dengan pola irama sesuai keinginan penata tari.

Proses penata tari dengan penata rias dan busana bedaya Putri Pakungwati diawali dengan pemilihan warna busana yaitu warna hijau, warna merah, putih dan warna kuning. Setelah pemilihan warna, penata busana mempertimbangkan kenyamanan penari untuk bergerak, bentuk baju maupun jarik yang digunakan. Desain bentuk busana bedaya Putri Pakungwati yaitu kebaya berwarna putih tanpa kancing ditutup dengan kemben berwarna hijau, bros dikaitkan sebagai pengganti kancing/hiasan pada kebaya, kain/jarik bermotif megamendung dengan dibentuk seperti rok, bagian ujung atas kain dilipat dan disatukan di bagian pinggang kanan lalu diikat menggunakan tali setelah itu ditutupi dengan kemben berwarna hijau, sabuk yang melilit di pinggang, menggunakan tiga sampur/soder yaitu warna kuning dan hijau yang dimasukkan ke dalam sabuk dengan sisi bagian kiri dan kanan yang simetris. Juntaian sampur bagian belakang dibentuk seperti bunga. Sampur/soder warna merah digunakan di bagian punggung kanan dan dimasukkan di bagian sabuk kiri bagian belakang. Semua keinginan penata tari dirancang oleh penata rias dan busana dengan memperhatikan kenyamanan penari dalam bergerak dan digunakan lengkap sebagai percobaan saat gladi resik untuk membenahi kekurangan pada busana.
Penata tari dengan penata panggung maupun penata cahaya sifatnya sangat kondisional. Menyesuaikan dimana dan luas ruangan area tari tersebut. Sehingga pada setiap pementasan, penata panggung memberikan arahan untuk menyesuaikan langsung kepada para penari yang dilakukan saat gladi resik. Proses kerjasama penata tari dengan penata lampu dimulai saat pertunjukan berlangsung. Untuk mencoba penataan lampu biasanya dilakukan saat technical run-through atau saat latihan terakhir general rehearsal. Penataan lampu tidak hanya sebatas penerangan saja tetapi, sekaligus penyinaran yang memberikan efek estetis. Penata lampu tari bedaya Putri Pakungwati hanya menggunakan general light. Efek yang dihasilkan dari general light untuk menerangi bagian yang ada dalam panggung secara keseluruhan.

\section{IV.}

Dari melihat proses kreatif karya tari bedaya Putri Pakungwati ide dasar penciptaan dan pemilihan judul merupakan gagasan langsung Sultan Sepuh XIV sebagai pencipta tari. Pemilihan gerak, properti maupun rias dan busana dipercayakan kepada Ibu Rohaeni, iringan tari dipercayakan kepada Bapak Inu Kertapati, untuk tata panggung, tata cahaya dipercayakan kepada kru secara kondisional sehingga tarian ini tidak memerlukan penanganan khusus dalam tata teknik pentas. Peran Sultan Sepuh XIV tidak hanya itu saja, tetapi beliau ikut mengevaluasi saat pementasan untuk mendapatkan karya tari yang diinginkan. Pengamatan tari maupun penataan iringan secara keseluruhan berpijak dari tari-tari gaya Cirebonan yang kemudian menghadirkan nafas-nafas baru untuk tari yang ada di Cirebon khususnya tari bedaya. Ciri khas dari bedaya Putri Pakungwati yaitu adanya penari tokoh, sebagai gambaran sosok Nyi Mas Ratu Pakungwati. Penari tokoh terlihat jelas pada perbedaan kain/jarik yang digunakan, beberapa motif gerak yaitu srisig soder dan srisig pasang soder penari tokoh 
hanya berputar ditempat, gerak nyawang yang dilakukan lebih awal secara canon dilanjutkan dengan penari dayang-dayang, dan pola lantai dominan paling depan dan tengah. Formasi pementasan bedaya Putri Pakungwati yang digunakan yaitu tiga, lima, tujuh bahkan sembilan namun dalam aspek gerak dan iringan tidak mengalami perubahan, hanya pola lantai yang berubah menyesuaikan sesuai formasi jumlah penari dan luasnya area tari.

\section{Daftar Sumber Acuan}

\section{A. Sumber Tertulis}

Al-Mundziri Imam. 2003. Ringkasan Shahih Muslim, terjemahan Achmad Zaidun. Jakarta: Jakarta Pustaka Amani.

Hadi, Y. Sumandiyo. 2012. Koreografi Bentuk-Teknik-Isi. Yogyakarta : Cipta Media.

Hawkins M, Alma. 1990. Mencipta Lewat Tari, terjemahan Y. Sumandiyo Hadi. Yogyakarta: ISI Yogyakarta.

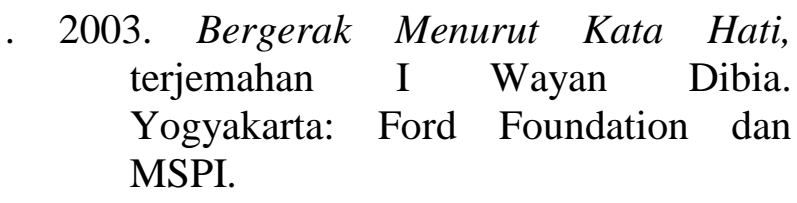

Murgiyanto, Sal. 1983. Koreografi Kemampuan Dasar Komposisi Tari. Jakarta: Depdikbud.

Noer, M Nurdin. 2009. Menusa Cerbon Sebuah Pengantar Budaya. Cirebon: Dinas Pemuda Olahraga Kebudayaan dan Pariwisata Kota Cirebon.

Soedarsono. 1972. Djawa dan Bali Dua Pusat Perkembangan Drama Tari Tradisional di Indonesia. Yogyakarta. Gadjah Mada University Press

Suharnan. 2011. Kreativitas Teori dan Pengembangan. Surabaya: Laros. Ramlan, Lalan. 2008. Tayub
Cirebonan. Bandung: Sunan Ambu Press.

\section{B. Narasumber}

1. Pangeran Raja Adipati Arief Natadiningrat, 51 tahun, pencipta tari Bedaya Putri Pakungwati.

2. Inu Kertapati, 38 tahun, penata iringan tari Bedaya Putri Pakungwati.

3. Rohaeni, 36 tahun, penata tari dan penata rias $\&$ busana tari bedaya Putri Pakungwati.

4. Elang Panji Jaya Pwawirakusuma, 59 tahun, sejarawan \& budayawan Keraton Kasepuhan. 
